\title{
The occurrence of leaf blight on Ophiopogon japonicus caused by Phyllosticta ophiopogonis in Korea
}

\author{
Jin-Hyeuk Kwon ${ }^{1}$ • Okhee Choi ${ }^{2}$ • Dong-Wan Kang ${ }^{1}$ • Won-Il Kim ${ }^{3}$ • Jinwoo Kim ${ }^{2,4}$
}

Received: 29 December 2014 / Accepted: 29 May 2015 /Published online: 13 June 2015

(C) Australasian Plant Pathology Society Inc. 2015

\begin{abstract}
A severe outbreak of Phyllosticta leaf blight was observed on mondo grass (Ophiopogon japonicas) in Jinju, South Korea during 2013-2014. Symptoms initially appeared on chlorotic leaves, followed by blight and finally leaf death. DNA sequencing and phylogenetic analysis of the internal transcribed spacer rRNA gene region confirmed that the isolate was Phyllosticta ophiopogonis. Koch's postulates were supported by pathogenicity tests conducted on healthy plants. Based on morphological characteristics, pathogenicity tests, and molecular analysis, the causal fungus was identified as P. ophiopogonis. To the best of our knowledge, this is the first report of leaf blight caused by $P$. ophiopogonis on mondo grass in South Korea.
\end{abstract}

Keywords Leaf blight · Phyllosticta ophiopogonis .

Mondo grass $\cdot$ rDNA spacer sequence

Ophiopogon japonicus. is called mondo grass and fountain grass. It is commonly used as one of the fundamental herbs in traditional Oriental medicine in China, Korea, and Japan. It

Jin-Hyeuk Kwon and Okhee Choi contributed equally to this work.

Jinwoo Kim

jinwoo@gnu.ac.kr

1 Gyeongsangnam-do Agricultural Research and Extension Services, Jinju 660-360, South Korea

2 Division of Applied Life Science (BK21Plus), Gyeongsang National University, Jinju 660-701, South Korea

3 Microbial Safety Team, National Academy of Agricultural Science, RDA, Jeonju 560-550, South Korea

4 Institute of Agriculture \& Life Science, Gyeongsang National University, Jinju 660-701, South Korea is also widely used as one of the most popular border plants and groundcover in South Korea, because of a wide range of tolerance for light, heat, humidity, drought and soil conditions.

Phyllosticta species are mostly plant pathogens of a wide range of hosts and are responsible for diseases including leaf spots and black spots on fruit (Wang et al. 2012; Wikee et al. 2013). There are 78 Phyllostica records associated with plant hosts in the USDA Fungal Database (Farr and Rossman 2014). A severe outbreak of Phyllosticta leaf blight was observed on mondo grass in Jinju, South Korea during 20132014. The first symptom on grafted mondo grass was chlorosis of the affected leaves. Severely infected leaves of mondo grass withered and blighted, after which whole plants eventually died (Fig. 1). Many small, black-colored pycnidia formed on the lesions (Fig. 2a). Pycnidia were dark brown, subglobose, and 95-100 × 75-80 $\mu \mathrm{m}$ (Fig. 2b). Conidia were unicellular, colorless, ovoid to oval, surrounded by a thick mucilaginous sheath that persists at maturity, 10-60 $\mu \mathrm{m}$ and a single, hyaline, curved or straight appendage (Fig. 2c, d). Spermatia were produced from spermatiogenous cells, cylindrical and globose at two ends, 6-10 × 1.3-1.6 $\mu \mathrm{m}$ (Fig. 2e). On PDA, colonies appeared woolly, initially white with abundant mycelium, gradually becoming greenish to dark green after 2-3 days with white hyphae on the undulate margin, eventually turning dark green to black. Colonies grow up to $40 \mathrm{~mm}$ in diameter on PDA after 14 days (Fig. 2f). Pycnidia appeared on the colonies after 7 days.

To isolate fungal pathogens from infected plant samples, leaf pieces (3-5 $\mathrm{mm}$ ) taken from the margins, including both symptomatic and healthy portions of leaf tissue, were surfacedisinfected in $1 \% \mathrm{NaOCl}$ solution for $30 \mathrm{~s}$, and then rinsed with sterilized distilled water three times and dried on sterilized filter paper. Leaf pieces were placed on water agar (WA) and incubated at $28{ }^{\circ} \mathrm{C}$. Mycelial tips grown on WA were transferred to potato dextrose agar (PDA) at $28{ }^{\circ} \mathrm{C}$ for 15 days. Five 
Fig. 1 Leaf blight symptoms on mondo grass caused by Phyllosticta ophiopogonis (a, b)
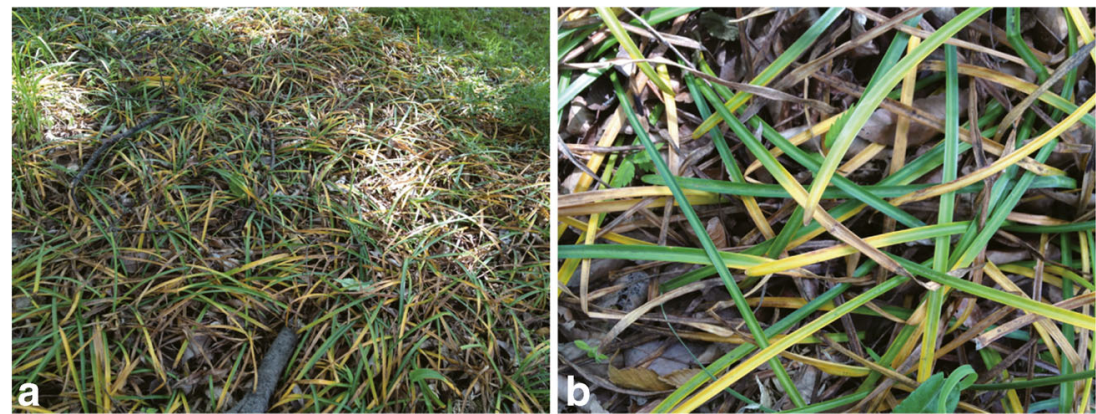

Phyllosticta isolates were isolated from infected plant samples. The representative fungal isolate was deposited with the Korean Agricultural Culture Collection (KACC 47754), National Academy of Agricultural Science, Rural Development Administration, Jeonju, South Korea. Detailed microscopic observations of a representative fungal isolate, KACC 47754, were performed under a light microscope (Axioplan, Carl Zeiss, Jena, Germany).

The complete ITS rRNA gene region of the representative fungal isolate (KACC 47754) was amplified using the ITS1 and ITS4 primers (White et al. 1990). Total DNA was extracted using the Exgene Plant-Fungal SV Mini Kit (GeneAll Biotechnolgy Co., Seoul, South Korea) following the manufacturer's instructions. Polymerase chain reaction (PCR) was performed on a thermal cycler (PC 802; Astec, Fukuoka, Japan) using the following conditions: $98^{\circ} \mathrm{C}$ for $2 \mathrm{~min}$, followed by 30 cycles of denaturation at $94{ }^{\circ} \mathrm{C}$ for $30 \mathrm{~s}$, annealing at $60{ }^{\circ} \mathrm{C}$ for $30 \mathrm{~s}$, and extension at $72{ }^{\circ} \mathrm{C}$ for $30 \mathrm{~s}$, with a final extension at $72{ }^{\circ} \mathrm{C}$ for $4 \mathrm{~min}$. Amplified products were separated by electrophoresis on $0.8 \%$ agarose gels. PCR products were purified using a Gel Extraction Kit (Qiagen, Hilden, Germany) and cloned using the pGEM-T Easy vector (Promega, Madison, WI, USA) according to the manufacturer's instructions. Plasmid DNA from white transformed Escherichia coli $\mathrm{DH} 5 \alpha$ colonies was extracted and purified using a plasmid extraction kit (GeneAll), and tested for the expected insert size by EcoRI (TaKaRa, Tokyo, Japan) digestion and visualization using gel electrophoresis and ethidium bromide staining. A resulting plasmid clone (pOR154) containing an insert of the expected size was isolated, and the insert was sequenced in both directions using the M13F and M13R primers at Macrogen Services (Daejeon, South Korea). The resulting 649-bp ITS rRNA gene sequences were deposited in GenBank (Accession no. KP197057). There is no type sequence of Phyllosticta ophiopogonis on GeBank. A nucleotide BLAST search had high sequence identity (99\%) to the corresponding ITS sequence in GenBank (Accession No. JN791616) from $P$. citrichinaensis strain ZJUCC200976 isolated from China that infects citrus.
Fig. 2 Morphological characteristics of Phyllosticta ophiopogonis: a Pycnidia on infected leaf; $\mathbf{b}$ vertical section through pycnidia showing developing conidia; $\mathbf{c}$ conidia; $\mathbf{d}$ conidia with sheath and appendage; e spermatia; f colony on PDA after 14 days of incubation $(\mathbf{b}-\mathbf{e}$ bars $=10 \mu \mathrm{m})$






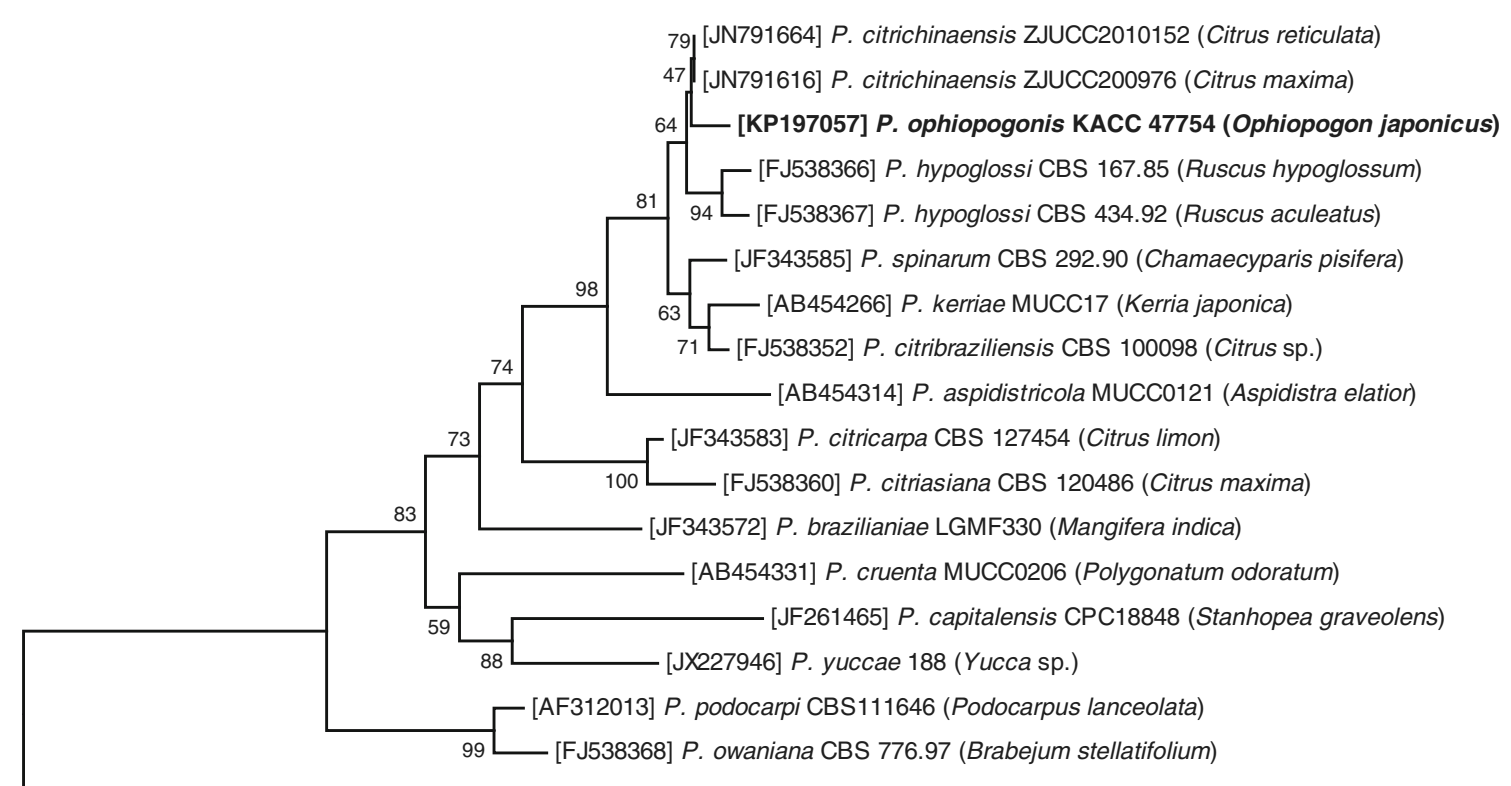

[AY972105] Botryosphaeria obtusa CMW8232

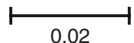

Fig. 3 Phylogenetic tree based on ITS sequences showing relationships among closely related Phyllosticta species. DNA sequences from the NCBI nucleotide database were aligned using the ClustalW program, and a phylogenetic tree was constructed using MEGA4.1 software with

Phylogenetic analysis was performed using MEGA4.1 software (http://www.megasoftware.net/mega4/mega41. html) with the neighbor-joining method and the Tajima-Nei distance model (Tamura et al. 2007). In phylogenetic analysis, ITS sequences of Phyllosticta strains were included as reference sequences (Wikee et al. 2013) and Botryosphaeria obtusa (GenBank Accession No. AY972105) was used as an outgroup (Wang et al. 2012; Wikee et al. 2012). The fungal isolate from mondo grass grouped with a clade in the phylogenetic tree comprising reference strains of Phyllosticta (Fig. 3).

To fulfill Koch's postulates, the inoculation techniques described by Zimowska (2014) were followed. Young healthy leaves of mondo grass were washed with sterilized distilled water, wiped with $70 \%$ ethanol and dried. A conidial suspension $\left(10^{7}\right.$ conidia $\left./ \mathrm{ml}\right)$ was obtained by rinsing the surface of the PDA cultures of the fungal isolate (KACC 47754) with sterilized distilled water. Five leaves were soaked in the suspension for 5 min (Roustaee et al. 2000; Zimowska 2014). Five leaves were soaked in sterilized distilled water as a control. All leaves were kept in a plastic box $(29 \times 22 \times 15 \mathrm{~cm})$ containing moistened filter paper at $>90 \%$ relative humidity and $28{ }^{\circ} \mathrm{C}$ for 10 days. Typical symptoms appeared 10 days after inoculation. All of the leaves inoculated with fungus produced similar symptoms that were identical with those of the naturally occurring disease. P. ophiopogonis was recovered from lesions and its identity was confirmed based on morphological characteristics. the neighbor-joining method and the Tajima-Nei distance model. Numbers above the branches indicate bootstrap values. Bars denote the number of nucleotide substitutions per site

P. kausarica was first reported as a pathogen of mondo grass in Pakistan (Khan 1962; Ahmad 1969; Ahmad et al. 1997; Farr and Rossman 2014) and O. intermedius in India (Sohi 1992). In 2012, Phyllosticta sp. caused a leaf spotting disease on mondo grass from Thailand, and was re-identified and reported as $P$. ophiopogonis sp. nov. based on symptoms and comparison of mycological characteristics with other Phyllosticta species described from Liliaceae (Wikee et al. 2012). Leaf blight caused by P. ophiopogonis has not been reported previously in Korea (The Korean Society of Plant Pathology 2009). Based on mycological characteristics, molecular data, and pathogenicity tests, the fungus was identified as $P$. ophiopogonis. To the best of our knowledge, this is the first report of $P$. ophiopogonis causing leaf blight on mondo grass in South Korea.

Acknowledgments This work was carried out with the support of "Cooperative Research Program for Agriculture Science \& Technology Development (Project No. PJ009192)" Rural Development Administration, Republic of Korea.

\section{References}

Ahmad S (1969) Fungi of West Pakistan. Biol Soc Pak Monogr 5:1-110 Ahmad S, Iqbal SH, Khalid AN (1997) Fungi of Pakistan. Sultan Ahmad Mycological Society of Pakistan, p. 248

Farr DF, Rossman AY (2014) Fungal databases, systematic mycology and microbiology laboratory, ARS, USDA. Internet Resource: http://nt.ars-grin.gov//fungaldatabases/ (verified June 30, 2014) 
Khan IU (1962) Leaf blight of lily turf. Biologia 8:49-50

Roustaee A, Dechamp-Guillaume G, Gelie B, Savy C, Dargent R, Barrault G (2000) Ultrastructural studies of the mode of penetration by Phoma macdonaldii in sunflower seedlings. Phytopathology 90: 915-920

Sohi HS (1992) Diseases of ornamental plants in India. Indian Council of Agricultural Research, New Delhi, p. 195

The Korean Society of Plant Pathology (2009) List of plant diseases in Korea. JY Press, Anyang

Tamura K, Dudley J, Nei M, Kumar S (2007) MEGA4: molecular evolutionary genetics analysis (MEGA) software version 4.0. Mol Biol Evol 24:1596-1599

Wang X, Chen G, Huang F, Zhang J, Hyde KD, Li H (2012) Phyllosticta species associated with citrus diseases in China. Fungal Divers 52: 209-224
White TJ, Bruns T, Lee S, Taylor JW (1990) Amplification and direct sequencing of fungal ribosomal RNA genes for phylogenetics. In: Innis MA, Gelfand DH, Sninsky JJ, White TJ (eds) PCR protocols: a guide to methods and applications. New York, Academic Press, pp. 315-322

Wikee S, Lombard L, Crous PW, Nakashima C, Motohashi K, Chukeatirote E, Alias SA, McKenzie EHC, Hyde KD (2013) Phyllosticta capitalensis, a widespread endophyte of plants. Fungal Divers 60:91-105

Wikee S, Wulandari NF, McKenzie EHC, Hyde KD (2012) Phyllosticta ophiopogonis sp. nov. from Ophiopogon japonicus (Liliaceae). Saudi J Biol Sci 19:13-16

Zimowska B (2014) Pathogenicity and ultrastructural studies of the mode of penetration by Phyllosticta plantaginis in ribwort leaves. Acta Sci Pol Hortorum Cultus 13:143-153 